\title{
Distribution of body mass index among subjects with COPD in the Middle East and North Africa region: data from the BREATHE study
}

This article was published in the following Dove Press journal:

International Journal of COPD

26 August 2015

Number of times this article has been viewed

Marie-Louise Koniski'

Hocine Salhi ${ }^{2}$

Aïcha Lahlou ${ }^{3}$

Nauman Rashid ${ }^{4}$

Abdelkader El Hasnaoui ${ }^{4}$

'Respiratory Division, Lebanese

American University Medical Center -

Rizk Hospital, Beirut, Lebanon;

${ }^{2}$ Foxymed, Paris, France; ${ }^{3} \mathrm{MS}$ Health, Rabat, Morocco; ${ }^{4}$ GlaxoSmithKline,

Dubai, United Arab Emirates
Correspondence: Marie-Louise Koniski University Medical Center - Rizk Hospital, Zahar Street, Achrafieh, P.O. Box II-3288, Beirut, Lebanon Tel +9613279030

Fax +96 I | 203324

Email marielouise.coussa@umcrh.com
Background: Data describing the potential relationship between chronic obstructive pulmonary disease (COPD) and body mass index (BMI) are limited within the Middle East and North Africa (MENA) region.

Objective: To evaluate the distribution of BMI among subjects with COPD in the general population of the MENA region.

Methods: This study was a subanalysis of the BREATHE study, a cross-sectional survey of COPD conducted in the general population of ten countries in the MENA region and Pakistan. The study population consisted of subjects screened for COPD who documented their weight and height. A COPD questionnaire was administered to subjects who screened positively for COPD in order to collect data on patient characteristics, symptom severity, management and burden of disease, comorbidities, and health care resource utilization and data allowing calculation of the BMI. The COPD Assessment Test (CAT) was administered to those screened positively for COPD to collect data on the impact of respiratory symptoms.

Results: Nine hundred and ninety-six subjects with COPD, who completed the detailed COPD questionnaire and documented their weight and height, were included in this analysis. The mean BMI was $27.7 \pm 5.7 \mathrm{~kg} / \mathrm{m}^{2}$. The proportion of COPD patients with a BMI $\geq 25 \mathrm{~kg} / \mathrm{m}^{2}$ is significantly higher than the proportion with a BMI $<25 \mathrm{~kg} / \mathrm{m}^{2}(64.6 \%$ [ $\mathrm{n}=643]$ vs $35.4 \%$ [ $\mathrm{n}=353$ ], respectively; $P<0.0001)$. There were no significant differences between the distribution of BMI, ages, sex, COPD symptoms, exacerbations, CAT scores, COPD-associated health care resource consumption, and GOLD severity groups. However, the occurrence of comorbidities such as diabetes and cardiovascular diseases seemed to be significantly associated with obese or morbidly obese status $(P=0.02)$.

Conclusion: In the MENA region, the majority of COPD subjects were overweight or obese, and comorbidities such as diabetes or cardiovascular diseases are likely to be associated with COPD when BMI is in the obese or morbidly obese ranges.

Keywords: COPD, BMI, association, MENA region

\section{Introduction}

Nutrition and weight management are increasingly being recognized as important factors in managing patients with chronic obstructive pulmonary disease (COPD). ${ }^{1}$ Studies have shown that patients with COPD, and particularly those with severe COPD, are at increased risk of malnutrition and weight loss as the disease progresses., ${ }^{2,3}$

The association between COPD and low body mass index (BMI) has also been established in many cross-sectional or cohort studies. ${ }^{46}$ For example, the PLATINO study from Latin America reported that, compared with subjects without COPD, a higher proportion of subjects fall into the underweight $\left(<20 \mathrm{~kg} / \mathrm{m}^{2}\right)$ and normal weight 
$\left(20-24.9 \mathrm{~kg} / \mathrm{m}^{2}\right)$ categories, and a lower proportion in the overweight and obese categories $\left(\geq 25 \mathrm{~kg} / \mathrm{m}^{2}\right.$ ) was detected. ${ }^{6}$ Moreover, it was reported in the literature that low BMI is an independent risk factor for mortality in subjects with COPD, ${ }^{7-10}$ and that the association is strongest in subjects with severe COPD. ${ }^{11}$ Patients with high BODE (BMI [B], the degree of airflow obstruction [O], dyspnea [D], and exercise capacity [E]) scores were at higher risk for death. The hazard ratio for death from any cause per one-point increase in the BODE score was 1.34 (95\% confidence interval [CI]: 1.26$1.42 ; P<0.001)$, and the hazard ratio for death from respiratory causes was 1.62 (95\% CI: $1.48-1.77 ; P<0.001) .{ }^{12}$

Data describing the potential relationship between COPD and BMI are limited within the Middle East and North Africa (MENA) region. The BREATHE study was an international study conducted in ten countries of the MENA region and in Pakistan, with the aim of estimating the prevalence of COPD symptoms in the general population, and to describe smoking habits, management and burden of COPD, and related health care utilization. ${ }^{13}$ The primary objective of this study was to evaluate the distribution of BMI among subjects with COPD in the general population of the MENA region, according to data from the BREATHE study database.

\section{Methods}

This analysis was performed using data from the BREATHE study, the methodology of which has been described in detail elsewhere. ${ }^{13}$ Briefly, this study was a cross-sectional epidemiological survey of COPD in a random sample of the general population in eleven countries: Algeria, Egypt, Jordan, Lebanon, Morocco, Pakistan, Saudi Arabia, Syria, Tunisia, Turkey, and UAE conducted between June 2010 and December 2011. The present analysis concerned the data relating to COPD and $\mathrm{BMI}$.

\section{Study sample}

This study was based on the population analyzed in the BREATHE study. ${ }^{13}$ All subjects who screened positively for COPD, completed a detailed COPD questionnaire, and providing data on weight and height were eligible for the present analysis.

\section{Data collection}

The present analysis was performed using data from three questionnaires administered in the BREATHE study. The first consisted of a screening questionnaire, which included 18 questions relating to patient demographics, self-reported respiratory symptoms (breathlessness and productive cough), chronic bronchitis, whether COPD, chronic bronchitis or emphysema had been diagnosed, and smoking habits (cigarettes or waterpipe). This questionnaire was completed by 62,086 subjects, ${ }^{13}$ and aimed to identify subjects who fulfilled an epidemiological case definition of COPD ( $\mathrm{N}=2,187$ subjects). ${ }^{14}$

For the epidemiological definition of COPD, cases were defined as eligible if they fulfilled both the following criteria:

1. Either: a) Diagnosis criterion: already diagnosed with COPD, emphysema or chronic bronchitis, or b) Symptom criterion: presenting either with symptoms that fulfill the definition of chronic bronchitis or with dyspnea; and

2. Smoking criterion: lifetime smoking exposure of $\geq 10$ pack-years.

The second set of questionnaires consisted of a detailed COPD questionnaire administered only to those members of the screened population who fulfilled the epidemiological case definition for COPD. A total of 2,187 COPD subjects were enrolled, with 1,392 of these subjects completing the second questionnaire. ${ }^{14}$ It should be noted that when comparing subjects with $\mathrm{COPD}(\mathrm{N}=2,187$ subjects) to the COPD population who completed the detailed questionnaire ( $N=1,392$ patient), there were no relevant differences in terms of demographics and COPD symptoms. ${ }^{14}$

The detailed COPD questionnaire consisted of 77 questions and collected data on risk factors, disease history, impact on daily life, patients' characteristics, symptom severity, management and burden of the disease, comorbidities, and health care resource utilization, including data allowing BMI to be calculated from replies to the two following questions: About how tall are you without shoes and what is your weight?

The BMI was thus calculated with the international definition based on body mass and body height. BMI was then categorized according to the World Health Organization classification $^{15}$ (underweight: $<18.5 \mathrm{~kg} / \mathrm{m}^{2}$; normal range: 18.5-25.0 kg/m²; overweight: $25.0-30.0 \mathrm{~kg} / \mathrm{m}^{2}$; obese: $30.0-35 \mathrm{~kg} / \mathrm{m}^{2}$; and morbidly obese: $\geq 35 \mathrm{~kg} / \mathrm{m}^{2}$ ).

The third questionnaire consisted of the COPD Assessment Test (CAT). ${ }^{16,17}$ The CAT scores document the impact of COPD on a patient's wellbeing and daily life through eight questions, each scored on a six-point Likert scale ranging from 0 to 5. A score $<10$ indicates a low impact, a score 10-19 a medium impact, and a score 20-40 a high to very high impact. The CAT scores were then used to classify subjects with COPD into four groups depending on their symptoms and risk of exacerbations, according to the recommendations of the 2011 GOLD report. ${ }^{18}$ Group A corresponds to low risk (no exacerbations) and less symptoms (CAT score $<10$ ), Group $\mathrm{B}$ corresponds to low risk and more symptoms (CAT $\geq 10$ ), Group C corresponds to high risk ( $\geq 1$ exacerbations) and less symptoms, and Group D corresponds to high risk and more 
symptoms. The presence of exacerbations was assessed over a period of 6 months. Since the exact number of exacerbations was not documented in the BREATHE study, the GOLD classification was adapted according to the presence (yes or no) of at least one exacerbation in the previous six months. The definition of exacerbation used in the BREATHE study has been described elsewhere. ${ }^{14}$

\section{Statistical analysis}

The present analysis was performed among subjects with COPD who completed the detailed COPD questionnaire and who documented their weight and height. The distribution of BMI among subjects with COPD, as well as the potential relationship between BMI categories and COPD symptoms, COPD-associated health care resources, CAT scores, the adapted-GOLD severity grade groups, and the presence of comorbidities were assessed. Data presented in this study are principally descriptive, and are presented as proportions and means with standard deviation. Frequency data were calculated with their 95\% confidence limits. The study variables were compared using the $\chi^{2}$ test and the Mantel-Haenszel test, as appropriate. The correlation between variables was assessed by using Pearson's correlation coefficient. All statistical tests were two-tailed with a probability level of 0.05 taken as the upper boundary for significance. Analyses were performed using SPSS Version 17 (SPSS Inc., Chicago, IL, USA).

\section{Ethics}

The study was conducted according to the principles of Good Epidemiological Practices. Participating subjects did not receive any financial compensation for their participation in the study. As the survey had no repercussions on patient care, no ethics committee authorization was required. The study was implemented by a specific contract research organization. All data collected was kept confidential and anonymous.

\section{Results \\ Study sample}

The analysis was performed on data pooled from all eleven participating countries. Of the 1,392 subjects with COPD who completed the detailed COPD questionnaire, ${ }^{14}$ a total of $996(71.6 \%)$ subjects documented their weight and height and thus represented the study population. The disposition of the analyzed population is presented in Figure 1.

The demographic characteristics of subjects with COPD who completed the detailed questionnaire (COPD population), and those of the study population (COPD population with documented BMI categories), are presented in Table 1. Overall, there were no relevant differences between the two populations. The majority of the study population were men (76.8\%), and the distribution of age groups was relatively homogenous. Approximately half of the study population

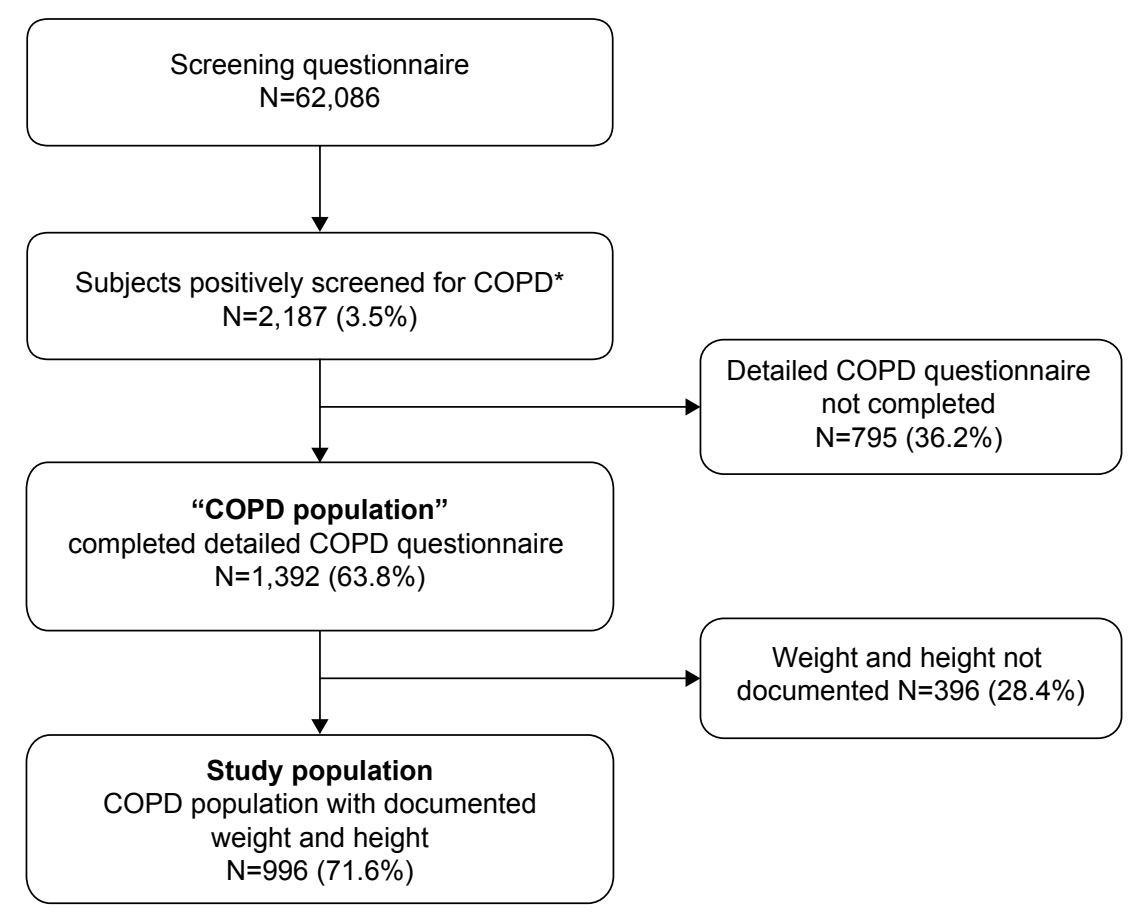

Figure I Disposition of the study population.

Notes: *COPD subjects fulfilling the COPD epidemiological definition used in the study. Proportions are calculated for each population with respect to the previous line. Abbreviation: COPD, chronic obstructive pulmonary disease. 
were employed and claimed to have good to excellent general health.

\section{Distribution of BMI categories in the COPD population}

The distribution of BMI in the COPD population is presented in Figure 2. The mean BMI was estimated at $27.7 \pm 5.7 \mathrm{~kg} / \mathrm{m}^{2}$. The proportion of subjects with COPD with a BMI $\geq 25 \mathrm{~kg} / \mathrm{m}^{2}$ is significantly higher than the proportion under this threshold (respectively $64.6 \%[\mathrm{n}=643]$ vs $35.4 \%[\mathrm{n}=353] ; P<0.0001$ ).

This distribution pattern was similar across sexes, although the mean BMI was slightly higher in women than in men $\left(27.9 \pm 5.9 \mathrm{~kg} / \mathrm{m}^{2}\right.$ and $27.6 \pm 5.7 \mathrm{~kg} / \mathrm{m}^{2}$, respectively; $P=0.49)$. Similarly, there were no significant differences in the distribution of BMI between age-groups $\left(27.3 \pm 5.7 \mathrm{~kg} / \mathrm{m}^{2}\right.$ in the 40-49 year old age group [ $\mathrm{n}=403], 27.9 \pm 5.9 \mathrm{~kg} / \mathrm{m}^{2}$ in the $50-59$ year old age group $[\mathrm{n}=326]$, and $27.4 \pm 5.6 \mathrm{~kg} / \mathrm{m}^{2}$ in the $\geq 60$ year old age group [n=267]; $P=$ not significant).

The distribution of COPD symptoms according to BMI categories was also investigated. Overall, the distribution was homogenous between BMI categories with respect to dyspnea (ranging from $65 \%$ to $90 \%$ of patients; $P=0.05$ ), with respect to persistent coughing with phlegm (ranging from $42 \%$ to $60 \%$ of patients; $P=0.92$ ), and with respect to chronic bronchitis (ranging from $22 \%$ to $57 \%$ of patients; $P=0.27$ ). Similarly, the use of COPD-associated health care resources was not different between BMI categories, with the exception of physician consultations. The proportion of patients who consulted a physician ranged from $62 \%$ to $80 \%(P=0.04)$, those who were hospitalized ranged from $19 \%$ to $43 \%(P=0.13)$, and those who visited an emergency room ranged from $18 \%$ to $24 \%(P=0.12)$. The proportion of patients experiencing a COPD exacerbation during the previous 6 months was also not associated with BMI distribution and ranged from $60 \%$ to $83 \%$ $(P=0.96)$. A respiratory treatment was used by the majority of COPD subjects with no differences between BMI categories (ranging from $70 \%$ to $83 \%$ of patients; $P=0.19$ ).

The distribution of BMI in the COPD population by country is presented in Figure 3. Overall, the highest proportion of COPD patients with a BMI $\geq 30 \mathrm{~kg} / \mathrm{m}^{2}$ (obese and morbidly obese categories), was detected in the Gulf countries, and the lowest proportion was detected in the Maghreb countries and Pakistan. The highest proportion of obese subjects with COPD was found in UAE $(43.6 \% ; n=7)$, and the highest proportion of morbidly obese subjects was detected in Saudi Arabia (14.7\%; n=21).

Table I Characteristics of the COPD population

\begin{tabular}{|c|c|c|c|}
\hline & $\begin{array}{l}\text { COPD population } \\
(\mathrm{N}=1,392)\end{array}$ & $\begin{array}{l}\text { COPD population with documented } \\
\text { BMI categories }(\mathrm{N}=996)\end{array}$ & $P$-value \\
\hline Sex, n (\%) & 1,392 & 996 & \\
\hline Women & $340(24.4)$ & $231(23.2)$ & 0.49 \\
\hline Men & I,052 (75.6) & $765(76.8)$ & 0.49 \\
\hline Age (years), n (\%) & 1,392 & 996 & \\
\hline $40-50$ & $535(38.4)$ & $403(40.5)$ & 0.32 \\
\hline $50-60$ & $487(35.0)$ & $326(32.7)$ & 0.25 \\
\hline$\geq 60$ & $370(26.6)$ & $267(26.8)$ & 0.90 \\
\hline Smoking status, n (\%) & 1,077 & 996 & \\
\hline Current & $695(64.5)$ & $647(65.0)$ & 0.84 \\
\hline Ex-smokers & $382(35.5)$ & $349(35.0)$ & 0.84 \\
\hline Educational level, n (\%) & 1,040 & 996 & \\
\hline No high school & $398(38.3)$ & $380(38.2)$ & 0.96 \\
\hline High school & $320(30.8)$ & $308(30.9)$ & 0.94 \\
\hline Technical college & $64(6.2)$ & $62(6.2)$ & 0.95 \\
\hline Undergraduate degree & $217(20.9)$ & $206(20.7)$ & 0.92 \\
\hline Post graduate degree & 41 (3.9) & $40(4.0)$ & 0.93 \\
\hline Employment status, n (\%) & 1,191 & 996 & \\
\hline Employed & $555(46.6)$ & $517(5 \mid .9)$ & 0.01 \\
\hline Unemployed & $453(38.0)$ & $306(30.7)$ & 0.0003 \\
\hline Homemaker & $173(14.5)$ & $163(16.4)$ & 0.23 \\
\hline Disabled/illness & $10(0.8)$ & $10(1.0)$ & 0.69 \\
\hline General health status, $\mathrm{n}(\%)$ & 1,388 & 996 & \\
\hline Excellent & $78(5.6)$ & $57(5.7)$ & 0.91 \\
\hline Very good to good & $618(44.5)$ & $462(46.4)$ & 0.37 \\
\hline Fair & $371(26.7)$ & $26 I(26.2)$ & 0.77 \\
\hline Poor to very poor & $321(23.1)$ & $216(21.7)$ & 0.41 \\
\hline
\end{tabular}




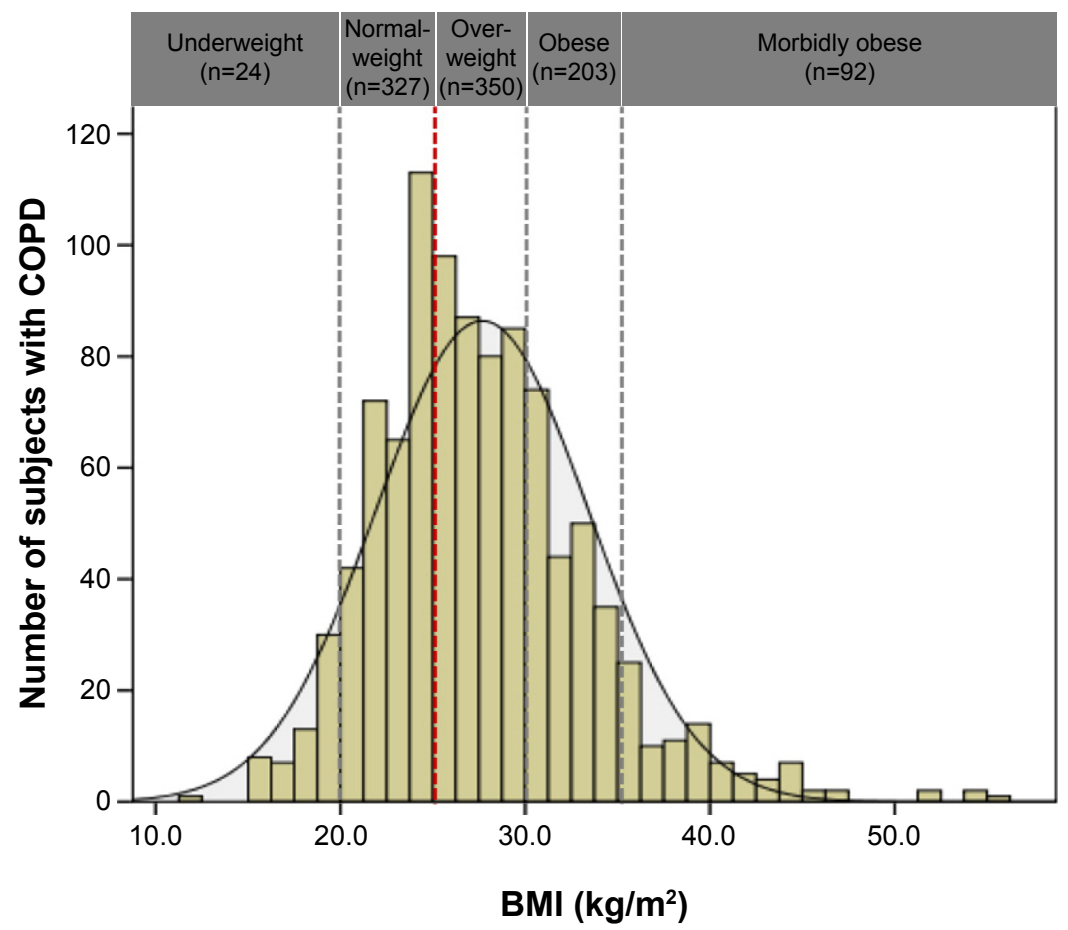

Figure 2 Distribution of BMI in COPD population.

\section{Distribution of BMI categories according to CAT scores}

Among the 996 subjects of the COPD population with documented BMI categories, a total of 951 (95.5\%) subjects completed the CAT questionnaire.
There was no significant correlation between the distribution of BMI and the distribution of CAT scores (Pearson's coefficient of correlation $=0.078$ ), and there was no significant difference (Student's $t$-test; $P=0.09$ ) between CAT score classes and the BMI categories (Table 2).
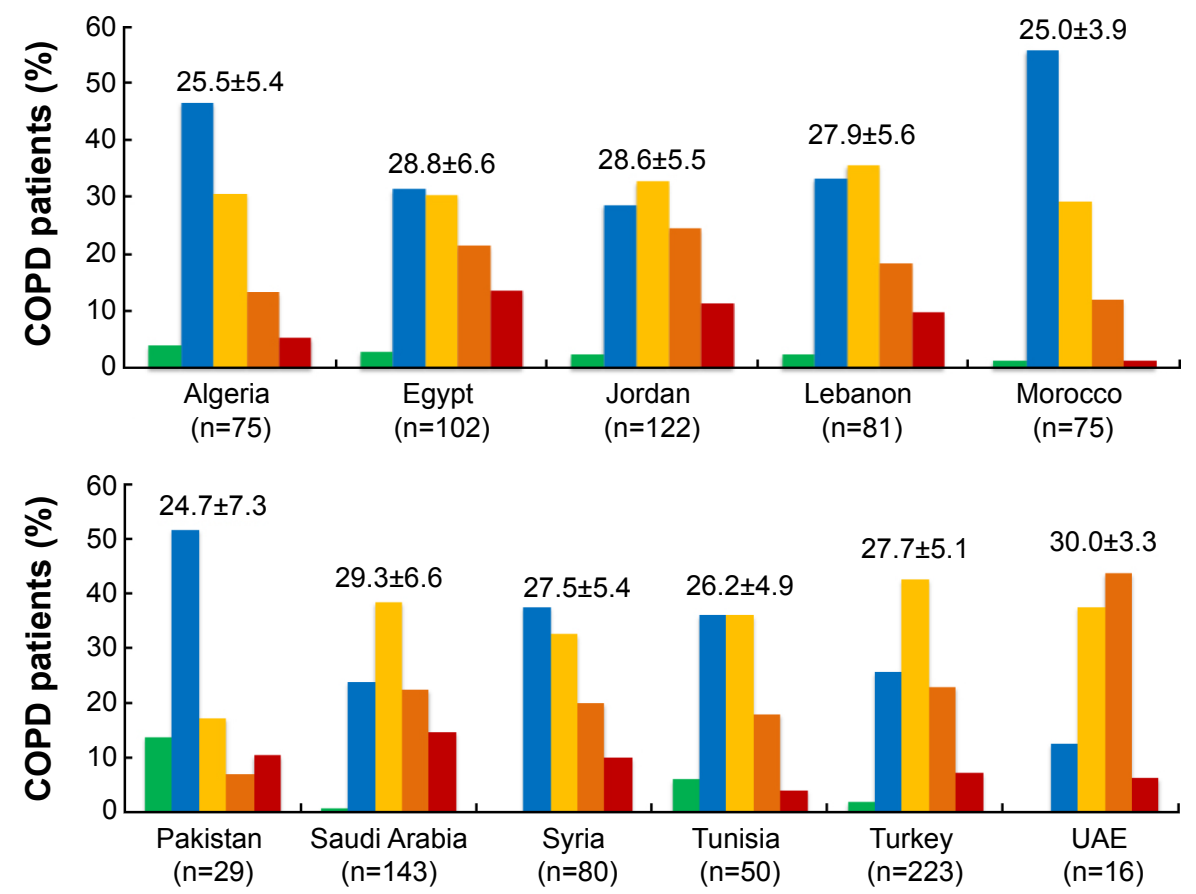

Figure 3 Distribution of BMI in COPD population according to each participant country. Green bars: underweight (BMI $\left.<20 \mathrm{~kg} / \mathrm{m}^{2}\right)$; blue bars: normal weight (BMI $20-25$ $\left.\mathrm{kg} / \mathrm{m}^{2}\right)$; yellow bars: overweight $\left(\mathrm{BMI} 25-30 \mathrm{~kg} / \mathrm{m}^{2}\right)$; orange bars: obese (BMl $\left.30-35 \mathrm{~kg} / \mathrm{m}^{2}\right)$; red bars: morbidly obese $\left(\mathrm{BMI} \geq 35 \mathrm{~kg} / \mathrm{m}^{2}\right)$. The mean $\mathrm{BMI}( \pm \mathrm{SD})$ is $\mathrm{provided}$ above the histograms for each country.

Abbreviations: BMI, body mass index; COPD, chronic obstructive pulmonary disease; SD, standard deviation. 
The BMI categories together with exacerbations and health care resources were entered into a multivariate logistic regression analysis of CAT scores; the results are presented in Figure 4. A significant independent association was found between a CAT score higher than 20 and an increasing use of emergency room visits (odds ratio [OR]: 3.16 [95\% CI: 2.09-4.77]), or a rising rate of COPD exacerbation (OR: 1.84 [95\% CI: 1.4-2.42]). In contrast, physician consultation seemed to be independently associated with a lower CAT score (OR: 0.55 [95\% CI: 0.42-0.73]). No independent association with hospitalization was found. With respect to BMI categories, there was no independent association between CAT score and lower (underweight), or upper (morbid obesity) classes. However, overweight and obesity seemed to be associated with a CAT score lower than 20.

\section{Distribution of BMI categories according to severity of symptoms and presence of comorbidities}

Among the COPD population with documented BMI categories, a total of 948 (95.2\%) subjects were classified into four severity groups based on their CAT score and on the presence of exacerbations, following the GOLD 2011 severity classification (Table 3).

For each BMI category, the majority of subjects were at a high risk of COPD exacerbation and experienced more symptoms (Group D). With respect to each GOLD severity group, no significant difference between BMI categories was detected (Mantel-Haenszel test; $P=0.67$ ).

The presence of comorbidities was documented by 951 subjects ( $95.5 \%$ of the study population). A higher rate of occurrence of comorbidities seemed to be significantly associated with obese or morbidly obese status (Mantel-Haenszel test; $P=0.02$ ) (Table 3 ). This is particularly relevant for the most common comorbidities detected in this study such as diabetes and cardiovascular diseases.

\section{Discussion}

This study assessed the distribution of BMI categories among a screened COPD population, derived from a randomly selected sample of the general population of eleven countries within the MENA region. The analysis was performed in 996 subjects enrolled in the BREATHE study who fulfilled the epidemiological definition of COPD, who completed the detailed COPD questionnaire, and documented their weight and height. This is the first study, to the best of our knowledge, that has evaluated the characteristics of subjects with COPD across different countries in the MENA region using a standardized methodology, in a region where obesity is a major public health issue.

This analysis showed that two-thirds of COPD subjects enrolled in the study had a BMI of $\geq 25 \mathrm{~kg} / \mathrm{m}^{2}$. The proportion of COPD subjects who were overweight was $35.1 \%$ $(n=350)$, those who were obese represented $20.4 \%(n=203)$, and morbidly obese subjects represented $9.2 \%(\mathrm{n}=92)$, with a slightly higher BMI in women than men. This high proportion is comparable with the findings of other epidemiological studies assessing the distribution of BMI among the general population in the region. For example, it was found that over the last decade, the prevalence of obesity has increased in the Gulf region, particularly in Saudi Arabia and Kuwait, perhaps as a consequence of the substantial economic growth of this region which has led to sedentarization and major changes in diet and lifestyle. In a review of studies based on the prevalence of obesity among the general population of six Gulf countries (Bahrain, Kuwait, Qatar, Oman, Saudi Arabia, and the UAE), it was reported that obesity (BMI $\geq 30 \mathrm{~kg} / \mathrm{m}^{2}$ ) affected approximately one-third of the adult population within this region, and a further $25 \%$ of the population were overweight (BMI $25-30 \mathrm{~kg} / \mathrm{m}^{2}$ ). ${ }^{19}$ For example, in Saudi Arabia, $36.0 \%$ of adults were obese and $32.7 \%$ were overweight, and an even higher prevalence rate of obesity was reported in Kuwait (42.1\% of adults). ${ }^{19}$ With respect to sex, obesity is more frequent in women than in men $(39.6 \%$ vs $30.0 \%),{ }^{19}$

Table 2 Distribution of CAT score classes according to BMI categories in COPD population

\begin{tabular}{|c|c|c|c|c|c|c|}
\hline & \multicolumn{5}{|c|}{ BMI score $\left(\mathrm{kg} / \mathrm{m}^{2}\right)$} & \multirow[t]{2}{*}{$P$-value } \\
\hline & $\begin{array}{l}\text { Underweight } \\
\text { ( }<18.5), \mathrm{n}=20\end{array}$ & $\begin{array}{l}\text { Normal } \\
(18.5-25.0), n=307\end{array}$ & $\begin{array}{l}\text { Overweight } \\
(25.0-30.0), n=339\end{array}$ & $\begin{array}{l}\text { Obese } \\
(30.0-35.0), n=196\end{array}$ & $\begin{array}{l}\text { Morbidly } \\
\text { obese ( } \geq 35), n=86\end{array}$ & \\
\hline CAT classes, n (\%) & & & & & & 0.09 \\
\hline$<10$ & $2(10.0)$ & $71(23.1)$ & $75(22.1)$ & $42(21.3)$ & $21(23.9)$ & \\
\hline $10-20$ & $6(30.0)$ & $125(40.7)$ & $132(38.9)$ & $68(34.5)$ & $19(21.6)$ & \\
\hline $20-30$ & $7(35.0)$ & $86(28.0)$ & $92(27.1)$ & $62(31.5)$ & $35(39.8)$ & \\
\hline$\geq 30$ & $5(25.0)$ & $25(8.1)$ & 40 (II.8) & $24(12.2)$ & II (I2.8) & \\
\hline CAT score $($ mean $\pm S D)$ & $22.6 \pm 10.0$ & $16.4 \pm 9.0$ & $17.4 \pm 9.5$ & $18.1 \pm 9.5$ & $19.1 \pm 10.3$ & 0.008 \\
\hline
\end{tabular}

Abbreviations: BMI, body mass index; CAT, COPD Assessment Test; COPD, chronic obstructive pulmonary disease; SD, standard deviation. 


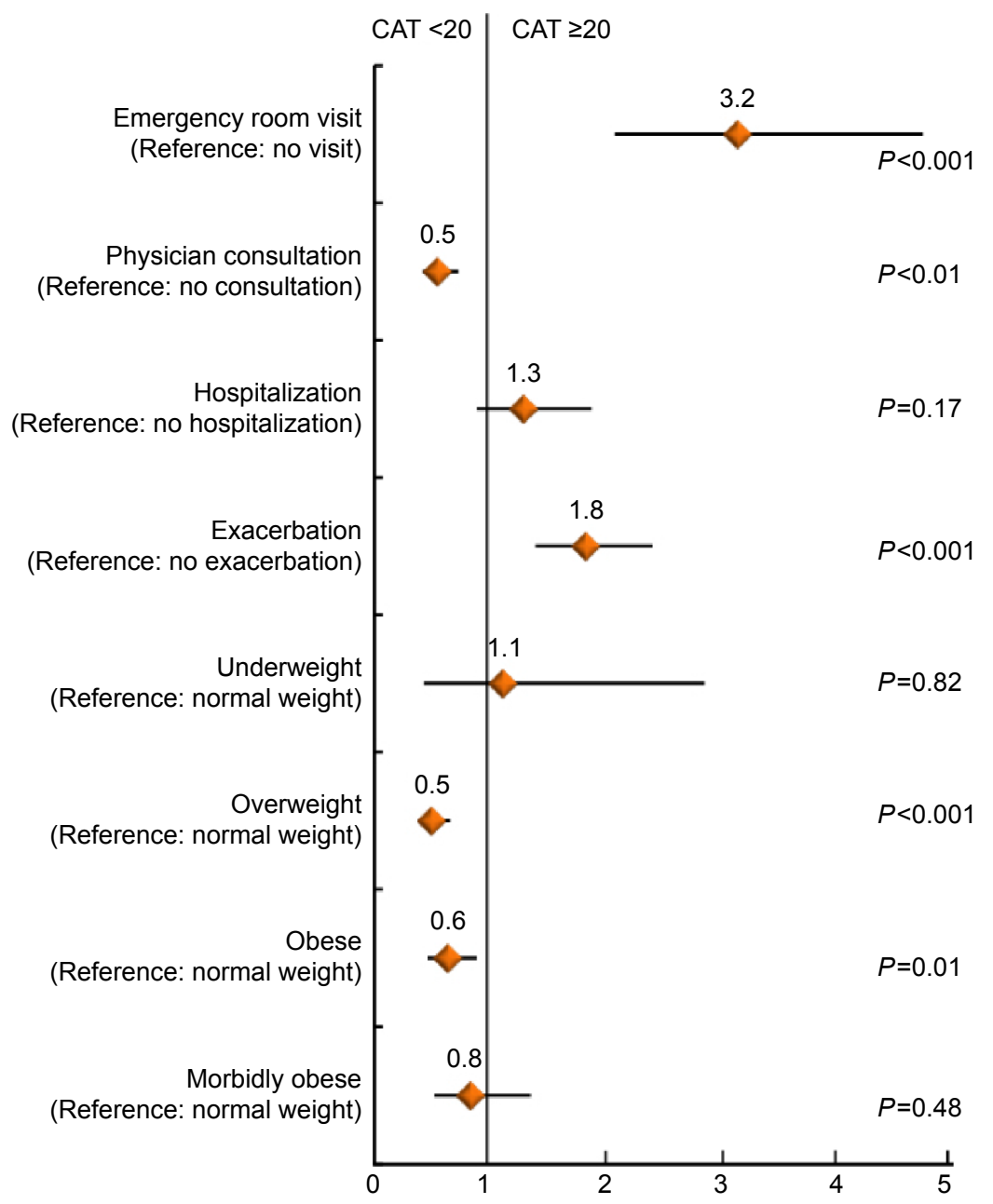

Figure 4 Variables associated with CAT scores identified by multiple logistic regression analysis.

Note: Data are presented as Forest diagrams showing odds ratios with $95 \%$ confidence intervals.

Abbreviation: CAT, COPD Assessment Test.

Table 3 Distribution of adapted GOLD severity groups and distribution of comorbidities according to BMI categories

\begin{tabular}{|c|c|c|c|c|c|c|}
\hline & \multicolumn{5}{|l|}{ BMI scores } & \multirow[t]{2}{*}{$P$-value } \\
\hline & $\begin{array}{l}\text { Underweight } \\
(<18.5) \\
\mathrm{n}=20\end{array}$ & $\begin{array}{l}\text { Normal } \\
(18.5-25.0) \\
n=307\end{array}$ & $\begin{array}{l}\text { Overweight } \\
(25.0-30.0) \\
n=339\end{array}$ & $\begin{array}{l}\begin{array}{l}\text { Obese } \\
(30.0-35.0) \\
n=196\end{array} \\
\end{array}$ & $\begin{array}{l}\text { Morbidly obese } \\
(\geq 35) \\
n=86\end{array}$ & \\
\hline $\begin{array}{l}\text { Group A (CAT score }<10 \text {, } \\
\text { no exacerbation), n (\%) }\end{array}$ & $2(10.0)$ & $42(13.7)$ & $51(15.0)$ & $28(14.3)$ & $12(14.0)$ & 0.67 \\
\hline $\begin{array}{l}\text { Group B (CAT score } \geq 10 \text {, } \\
\text { no exacerbation), n (\%) }\end{array}$ & I (05.0) & $75(24.4)$ & $82(24.2)$ & $47(24.0)$ & $14(16.3)$ & \\
\hline $\begin{array}{l}\text { Group C (CAT score }<10 \text {, } \\
\text { exacerbation), n (\%) }\end{array}$ & $0(00.0)$ & $29(09.4)$ & $24(07.1)$ & $14(07.1)$ & $9(10.5)$ & \\
\hline $\begin{array}{l}\text { Group D (CAT score } \geq 10 \text {, } \\
\text { exacerbation), } n(\%)\end{array}$ & $17(85.0)$ & I6I (52.4) & $182(53.7)$ & $107(54.6)$ & $51(59.3)$ & \\
\hline Comorbidities, n (\%) & $13(65.0)$ & I 47 (47.9) & $169(49.9)$ & $101(51.3)$ & $60(68.2)$ & 0.024 \\
\hline Asthma, n (\%) & $0(00.0)$ & $10(03.3)$ & $22(06.5)$ & $20(10.2)$ & $7(08.0)$ & 0.016 \\
\hline Diabetes, n (\%) & $4(20.0)$ & $31(10.1)$ & $64(18.9)$ & $45(22.9)$ & $31(35.3)$ & $<0.0001$ \\
\hline Cardiovascular diseases, n (\%) & $3(15.0)$ & $60(19.5)$ & $86(25.4)$ & $57(28.9)$ & $4 \mathrm{I}(46.6)$ & $<0.0001$ \\
\hline
\end{tabular}

Notes: Only the three first documented comorbidities are presented; $P$-values were calculated with the Mantel-Haenszel test.

Abbreviations: BMI, body mass index; CAT, COPD Assessment Test; GOLD, Global initiative for chronic obstructive lung disease. 
which is also found in this study, but with a lower interval range between women and men (35.9\% vs 34.6\%). The high proportion of COPD subjects with a BMI of $\geq 25 \mathrm{~kg} / \mathrm{m}^{2}$ is also comparable with the findings of other epidemiological studies assessing the distribution of BMI among COPD subjects. For example, a retrospective study assessing the effect of BMI on lung function among 2,265 subjects with COPD over a 16 year duration in Canada, showed a similar distribution of COPD subjects according to BMI categories compared with this study, and that approximately $30 \%$ of COPD subjects had BMI values in the obesity range. ${ }^{16}$ Furthermore, a subanalysis of the large epidemiological PLATINO study assessed the distribution of BMI categories among 759 subjects with COPD in five Latin-American cities (São Paulo, Santiago, Mexico City, Montevideo, Caracas). This analysis showed that approximately two-thirds (64\%) of COPD subjects had a BMI of $\geq 25 \mathrm{~kg} / \mathrm{m}^{2}$, with $23 \%$ in the obesity range. ${ }^{6}$

It has been reported elsewhere in the literature that severe COPD was associated with a low BMI. ${ }^{3}$ We did not observe this in our sample, because the majority of COPD subjects were classified in the most severe group (Group D), no matter what the BMI category. As the prevalence of obesity among the general population within the MENA region was approximately ten times higher than the prevalence of COPD, which was estimated to be approximately $4 \%$ in the BREATHE study, ${ }^{17}$ the probability of the presence of obesity as a comorbidity in our COPD subjects is likely to be higher than other COPD populations in the world where the prevalence of obesity is low. In addition, BMI distrbution in our study population, and particularly the categories with a BMI of $\geq 25 \mathrm{~kg} / \mathrm{m}^{2}$, is likely to be comparable with BMI categories in the general population within the MENA region, but potentially different from BMI categories among other COPD populations around the world.

Although obesity is not considered as an absolute risk factor for COPD, there is clinical evidence suggesting a relationship between the severity of COPD and obesity, ${ }^{16}$ which is associated with a worsening of COPD symptoms and a decrease in both exercise tolerance and quality of life. ${ }^{20}$ The occurrence of comorbidities, such as diabetes or cardiovascular disease in the COPD population analyzed in this study, is significantly associated with obese or morbidly obese status $(P=0.02)$. It is known that the prevalence of diabetes in the general population of the MENA region is one of the highest in the world, and has been estimated to be $9.7 \%$, in $2014^{21}$ whereas the overall worldwide prevalence is estimated to be $8.3 \%$. Consequently in this study, the COPD population, derived from a randomly selected sample of the general populations within the MENA region, is inherently more likely to have diabetes compared with other comorbidities with a lower incidence. Moreover, the association between diabetes and obesity found in our study is also well characterized and well documented by studies performed in the general population or in the COPD population. For example, a meta-analysis of 18 studies assessing the magnitude of the relative risk of developing type 2 diabetes for overweight and obese populations compared with those with normal weight, revealed that the overall relative risk of diabetes for obese persons compared with those with normal weight was 7.19 [95\% CI: 5.74-9.00]. ${ }^{22}$ Among the COPD population, it has been reported in two large prospective US studies that a BMI value in the obesity range is significantly associated with diabetes. ${ }^{23,24}$

The current analysis showed that there was no strong association between CAT scores and BMI distribution, consistent with findings of other studies which have failed to demonstrate an association between the CAT score and $\mathrm{BMI}$ in general ${ }^{25}$ and with the presence of obesity in particular. ${ }^{26}$ In addition, we found that the CAT score was higher in underweight subjects, which is comparable with the results of a Japanese study assessing comorbid factors associated with CAT scores. This study revealed that the CAT score in underweight patients (16.9 \pm 9.4$)$ was higher than those in the normal (12.0 \pm 8.1$)$, and overweight patients $(11.1 \pm 7.2){ }^{25}$

The interest of this study lies in the fact that it is one of the first studies to assess the distribution of BMI among a large sample of subjects with COPD within the MENA region, using a standardized methodology and collecting comparable data in the eleven participating countries. The study included a representative sample of the general population of each country and took into account the disparities in the health care systems and practices between participating countries. This study used an epidemiological case definition of COPD, inspired from that used in the Confronting COPD international studies, ${ }^{27}$ performed in North America and Europe, and the GOLD guidelines for the diagnosis of COPD. ${ }^{28,18}$ The choice of identifying cases from the response to three different questionnaires has the advantage of ensuring a large and representative sample, but can lead to some inaccuracies due to the lack of physician ascertainment in the diagnosis of COPD, and to lack of access to clinical data that can only be provided by a physician, notably spirometry. The alternative choice of recruiting patients through physicians would have provided the opportunity to collect more complete and precise data, but at the expense of a loss of representativeness of the sample and thus of the comparability of the data 
between countries. In addition, this choice would have led to the exclusion of individuals with COPD who are undiagnosed or not regularly followed by a physician, which may represent an important segment of the population in certain countries of the study.

This study presents certain limitations, most of which are related to the methodology, and have been described in detail elsewhere, and these should be kept in mind when interpreting the data. ${ }^{13}$ As previously mentioned, this study collected data from a subject's perspective without any possibility for physician ascertainment. This may introduce a source of anamnestic error and also some inaccuracy due to the lack of physician ascertainment particularly if subjects misunderstood the diagnosis or did not know, or report, their exact weight and height at the time of the interview. Moreover, we did not collect data on the distribution of BMI among non-COPD subjects, because only individuals with COPD completed the screening questionnaire. The comparison between COPD and non-COPD subjects and the assessment of the potential relationship between the presence of COPD and one of the BMI categories are important issues and these cannot be addressed in this study. The proportion of COPD subjects in the underweight category is low compared with the other categories, reflecting on the proportion of subjects with a low BMI in the general population of the participating countries. However, the same figures were reported in other large studies around the world. ${ }^{6,16}$

\section{Conclusion}

This study showed that within the MENA region the majority ofCOPD subjects were overweight or obese (BMI $\geq 25 \mathrm{~kg} / \mathrm{m}^{2}$ ), and that comorbidities such as diabetes or cardiovascular disease, are likely to be associated with COPD when BMI is in the obese or morbidly obese range. It also showed that there was no strong association between CAT scores and BMI distribution and that there was no significant relation between BMI and the severity of COPD. Such findings suggest that the role of obesity in COPD is of important significance. These findings underline the need to increase awareness in patients and physicians about the possible coexistence of these prevalent chronic diseases, which are considered as among the principal cause of death in the world, and therefore, warrant further study.

\section{Acknowledgments}

This study was initiated and funded by GlaxoSmithKline (the study sponsor). The study sponsor designated a scientific committee of respiratory diseases specialists to advise on the design, implementation, and interpretation of the study results. These specialists had full access to all data from the study, could request further analyses, and were actively involved in the preparation of this article. The committee members received financial compensation from the sponsor in return for their participation. Data analyses were delegated by the study sponsor to MS Health (Rabat, Morocco), an independent clinical research organization. The study sponsor funded editorial support from a medical writing agency (Foxymed, Paris, France) for the preparation of this article. The corresponding author had full access to all the data and had final responsibility for the decision to submit the manuscript for publication.

\section{Author contributions}

MLK, NR, and AEH developed the hypotheses and conceived the analysis plan. AL performed the statistical analyses. All authors contributed to the analysis and interpretation of the study results. HS wrote the first draft of the manuscript. All authors participated in the revision of the manuscript and agree to be accountable for all aspects of the work. All authors approved the submission of this final draft.

\section{Disclosure}

MLK has received honoraria from GlaxoSmithKline Laboratories for her contribution to the BREATHE study. AL is an employee of MS Health, the clinical and epidemiological research company responsible for the implementation, the collection of data and the statistical analysis of the results of the BREATHE study. HS is an employee of Foxymed, a medical communication and consultancy company who participated in the exploration, interpretation of the results, and preparation of this manuscript on behalf of GlaxoSmithKline Laboratories. Foxymed also provided medical writing support in the form of writing assistance, collating author's comments, grammatical editing, and referencing that was paid for by GSK. NR and AEH are employees of GlaxoSmithKline Laboratories, which funded the BREATHE study and market a number of treatments for COPD, and own shares in the company. The authors report no other conflicts of interest.

\section{References}

1. Global Initiative for Chronic Obstructive Lung Disease. Global Strategy for the Diagnosis, Management and Prevention of Chronic Obstructive Pulmonary Disease (Updated 2013). Boston (MA): Global Initiative for Chronic Obstructive Lung Disease; 2013.

2. Rutten E, Wouters E, Franssen F. Malnutrition and obesity in COPD Eur Respir Mon. 2013;59:80-92.

3. Harik-Khan RI, Fleg JL, Wise RA. Body mass index and the risk of COPD. Chest. 2002;121:370-376. 
4. Menezes AM, Perez-Padilla R, Jardim JR, et al. Chronic obstructive pulmonary disease in five Latin American cities (the PLATINO study): a prevalence study. Lancet. 2005;366:1875-1881.

5. Zhong N, Wang C, Yao W, et al. Prevalence of chronic obstructive pulmonary disease in China: a large, population-based survey. Am J Respir Crit Care Med. 2007;176:753-760.

6. Montes de Oca M, Talamo C, Perez-Padilla R, et al. Chronic obstructive pulmonary disease and body mass index in five Latin America cities: the PLATINO study. Respir Med. 2008;102:642-650.

7. Vestbo J, Prescott E, Almdal T, et al. Body mass, fat-free body mass, and prognosis in patients with chronic obstructive pulmonary disease from a random population sample: findings from the Copenhagen City Heart Study. Am J Respir Crit Care Med. 2006;173:79-83.

8. Schols AM, Slangen J, Volovics L, et al. Weight loss is a reversible factor in the prognosis of chronic obstructive pulmonary disease. Am J Respir Crit Care Med. 1998;157:1791-1797.

9. Yang L, Zhou M, Smith M, et al. Body mass index and chronic obstructive pulmonary disease-related mortality: a nationally representative prospective study of 220,000 men in China. Int J Epidemiol. 2010;39:1027-1036.

10. Cao C, Wang R, Wang J, et al. Body mass index and mortality in chronic obstructive pulmonary disease: a meta-analysis. PLOS ONE 2012; 7:e43892.

11. Landbo C, Prescott E, Lange P, et al. Prognostic value of nutritional status in chronic obstructive pulmonary disease. Am J Respir Crit Care Med. 1999;160:1856-1861.

12. Celli BR, Cote CG, Marin JM, et al. The body-mass index, airflow obstruction, dyspnea, and exercise capacity index in chronic obstructive pulmonary disease. $N$ Engl J Med. 2004;350:1005-1012.

13. El Hasnaoui A, Rashid N, Lahlou A, et al. Chronic obstructive pulmonary disease in the adult population within the Middle East and North Africa region: rationale and design of the BREATHE study. Respir Med. 2012;106:S3-S15.

14. Idrees M, Koniski ML, Taright S, et al. Management of chronic obstructive pulmonary disease in the Middle East and North Africa region: results of the BREATHE study. Respir Med. 2012;106:S33-S44.

15. World Health Organization. BMI Classification. Global Database on Body Mass Index. Geneva: World Health Organization; 2006. Available from www.who.int/bmi. Accessed August 2, 2015.

16. O'Donnell DE, Deesomchok A, Lam YM, et al. Effects of BMI on static lung volumes in patients with airway obstruction. Chest. 2011;140: 461-468.

17. Tageldin MA, Nafti S, Khan JA, et al. Distribution of COPD-related symptoms in the Middle East and North Africa region: results of the BREATHE study. Respir Med. 2012;106:S25-S32.
18. Global Initiative for Chronic Obstructive Lung Disease. Global Strategy for the Diagnosis, Management and Prevention of Chronic Obstructive Pulmonary Disease. Boston (MA): Global Initiative for Chronic Obstructive Lung Disease; 2011.

19. Ng SW, Zaghloul S, Ali HI, et al. The prevalence and trends of overweight, obesity and nutrition-related non-communicable diseases in the Arabian Gulf States. Obes Rev. 2011;12:1-13.

20. Vozoris NT, O'Donnell DE. Prevalence, risk factors, activity limitation and health care utilization of an obese, population-based sample with chronic obstructive pulmonary disease. Can Respir J. 2012;19: e18-e24.

21. Diabetes Atlas. 6th ed. [database on the Internet] 2014 Update. Available from: http://www.idf.org/diabetesatlas. Accessed August 2, 2015.

22. Abdullah A, Peeters A, de Courten M, et al. The magnitude of association between overweight and obesity and the risk of diabetes: a meta-analysis of prospective cohort studies. Diabetes Res Clin Pract. 2010;89:309-319.

23. Ford ES, Mannino DM. Prospective association between lung function and the incidence of diabetes: findings from the National Health and Nutrition Examination Survey Epidemiologic Follow-up Study. Diabetes Care 2004;27:2966-2970.

24. Mannino DM, Thorn D, Swensen A, et al. Prevalence and outcomes of diabetes, hypertension and cardiovascular disease in COPD. Eur Respir J. 2008;32:962-969.

25. Miyazaki M, Nakamura H, Chubachi S, et al. Analysis of comorbid factors that increase the COPD assessment test scores. Respir Res 2014; 15:13.

26. Mackay AJ, Donaldson GC, Patel AR, et al. Usefulness of the chronic obstructive pulmonary disease assessment test to evaluate severity of COPD exacerbations. Am J Respir Crit Care Med. 2012;185: $1218-1224$.

27. Rennard S, Decramer M, Calverley PM, et al. Impact of COPD in North America and Europe in 2000: subjects' perspective of Confronting COPD International Survey. Eur Respir J. 2002;20:799-805.

28. Rabe KF, Hurd S, Anzueto A, et al. Global strategy for the diagnosis, management, and prevention of chronic obstructive pulmonary disease: GOLD executive summary. Am J Respir Crit Care Med. 2007;176: $532-555$.
International Journal of COPD

\section{Publish your work in this journal}

The International Journal of COPD is an international, peer-reviewed journal of therapeutics and pharmacology focusing on concise rapid reporting of clinical studies and reviews in COPD. Special focus is given to the pathophysiological processes underlying the disease, intervention programs, patient focused education, and self management protocols.

\section{Dovepress}

This journal is indexed on PubMed Central, MedLine and CAS. The manuscript management system is completely online and includes a very quick and fair peer-review system, which is all easy to use. Visit http://www.dovepress.com/testimonials.php to read real quotes from published authors. 